\title{
Pengaruh Diskriminasi Kerja Pada Restoran Soerabi Bandung HNH
}

\author{
Jainudin, Intan F. ${ }^{1}$, Pitaloka, E. ${ }^{1}$ \\ Program Studi Manajemen, Universitas Pembangunan Jaya \\ 1intanjainudin@gmail.com \\ ºka@upj.ac.id
}

\begin{abstract}
The purpose of this study is to analyze the influence of workplace discrimination on organizational commitment, either directly or through job stress towards employees in the Soerabi Bandung HNH restaurant. In this study, 30 employees were selected as respondents. The research instrument used a questionnaire, were analyzed using SPSS and AMOS. Results from this study showed that the variables of workplace discrimination does not affect the commitment of the organization. Workplace discrimination significantly affect organizational commitment through job stress.
\end{abstract}

Keywords : workplace discrimination, job stress, organizational commitment, restaurant

\begin{abstract}
Abstrak : Penelitian ini bertujuan untuk menganalisa pengaruh diskriminasi kerja terhadap komitmen organisasi baik secara langsung maupun melalui stress kerja pada karyawan di restoran Soerabi Bandung HNH. Responden penelitian ini adalah 30 karyawan di restoran. Instrumen penelitian yang digunakan berupa kuesioner. Data kuesioner yang telah diisi kemudian diolah menggunakan SPSS dan AMOS. Hasil penelitian menunjukkan bahwa variabel diskriminasi kerja tidak berpengaruh terhadap komitmen organisasi secara langsung. Diskriminasi kerja berpengaruh secara signifikan terhadap komitmen organisasi melalui stres kerja.
\end{abstract}

Kata Kunci : diskriminasi kerja, stres kerja, komitmen organisasi, restoran

\section{LATAR BELAKANG}

Pada era globalisasi sekarang ini, pertumbuhan ekonomi di Indonesia mengalami perkembangan yang cukup pesat. Hal tersebut termasuk dalam perkembangan industri jasa. Perkembangan tersebut diikuti dengan banyaknya perusahaan, dan dapat menyebabkan terjadinya persaingan antar perusahaan, terutama perusahaan yang bergerak dalam bidang yang sama. Setiap perusahaan berusaha untuk menentukan strategi yang tepat agar bisa mendapatkan dan mempertahankan konsumen.

Sumber Daya Manusia memiliki peran penting untuk perusahaan dalam menghadapi persaingan antar perusahaan.
Perusahaan harus memiliki komitmen dalam organisasi agar dapat menciptakan dan mengembangkan potensi bisnis. Selain itu, perusahaan harus menciptakan lingkungan kerja yang kondusif agar karyawan dapat bekerja dengan optimal dan kompetitif.

Komitmen organisasi adalah sejauh mana seorang karyawan mengidentifikasi dirinya dengan organisasi tertentu dan tujuan dan keinginan untuk mempertahankan keanggotaan dalam organisasi (Robbins \& Judge, 2011). Komitmen organisasional berperan untuk memajukan perusahaan karena menunjukkan sikap yang kuat dari karyawan untuk mencapai tujuan 
organisasi. Komitmen organisasi penting untuk menentukan berhasil atau tidak sebuah perusahaan dalam mencapai tujuan. Komitmen organisasional dipengaruhi oleh stres kerja. Hasil suatu penelitian menunjukkan bahwa komitmen organisasi dan kepuasan kerja dipengaruhi oleh stres kerja (Masihabadi, et al., 2015). Stres adalah ketegangan atau tekanan emosional yang dialami seseorang yang sedang menghadapi tuntutan yang sangat besar atau kesempatan melakukan sebuah kegiatan penting, yang dalam pemenuhannya terdapat hambatanhambatan dan ketidakpastian yang dapat mempengaruhi emosi, pikiran, dan kondisi fisik seseorang (Badeni, 2013). Stres yang tidak bisa diatasi dengan baik biasanya berakibat pada ketidakmampuan orang berinteraksi secara positif dengan lingkungannya, baik dalam lingkungan pekerjaan maupun lingkungan luarnya. Stres memiliki dampak terhadap karyawan yaitu dalam faktor pekerjaan dan lingkungan kerja (organisasi), lingkungan, dan faktor individu.

Stres kerja dipengaruhi oleh diskriminasi yang ada di suatu organisasi. Hasil suatu penelitian menunjukkan bahwa diskriminasi gender meningkatkan tingkat stres (Channar, et al., 2011). Diskriminasi adalah perlakuan yang berbeda dari individu atau kelompok berdasarkan askriptif sewenang-wenang atau memperoleh kriteria seperti jenis kelamin, ras, agama, usia, perkawinan atau status orang tua, cacat, orientasi seksual, opini politik, dan latar belakang sosial-ekonomi. (Eurofound, 2012). Diskriminasi dapat terjadi karena gaji, promosi, perekrutan, jenis kelamin dan umur, sosial budaya, dan ajaran agama.

Penelitian ini dilakukan di restoran Soerabi Bandung HNH yang terletak di Kebayoran, Gandaria, Jakarta. Soerabi Bandung $\mathrm{HNH}$ memiliki karyawan yang beragam. Sumber Daya Manusia di Soerabi Bandung HNH berkaitan dengan komitmen organisasional, apakah karyawan tersebut tetap loyal kepada restoran walaupun merasakan diskriminasi dan menyebabkan stres kerja. Oleh karena itu penelitian ini mengkaji tentang "Diskriminasi Kerja yang Terjadi di Restoran Soerabi Bandung HNH".

\section{LANDASAN TEORI Diskriminasi}

Diskriminasi menurut Eurofound (2012) didefinisikan sebagai "different treatment of individuals or groups based on arbitrary ascriptive or acquires criteria such as sex, race, religion, age, marital or parental status, disability, sexual orientation, political opinions, socioeconomic background, and trade union membership and activities", yang artinya perlakuan yang berbeda dari individu atau kelompok berdasarkan askriptif sewenangwenang atau memperoleh kriteria seperti jenis kelamin, ras, agama, usia, perkawinan atau status orang tua, cacat, orientasi seksual, opini politik, latar belakang sosial-ekonomi, dan serikat pekerja keanggotaan dan kegiatan.

Sehingga dapat disimpulkan bahwa diskriminasi adalah perlakuan tidak adil yang dilakukan terhadap seorang individu yang membuat individu tersebut merasa tidak nyaman berada di masyarakat. Dalam hal ini, dari perlakuan yang berbeda tersebut (seperti jenis kelamin dan usia) dapat terlihat apakah seseorang mengalami diskriminasi dan menyebabkan stres kerja yang kemudian dapat mempengaruhi komitmen karyawan terhadap organisasi.

Diskriminasi bervariasi pada faktor gaji, promosi, dan perekrutan (Imam \& Shah, 2013) serta jenis kelamin dan usia, sosial budaya, dan ajaran agama (Suardi, 2016) yang dapat digunakan untuk mengukur diskriminasi kerja. Faktor biologi dapat berupa jenis kelamin dan usia seseorang, maka diskriminasi juga bervariasi pada faktor jenis kelamin dan usia seseorang (Kadiresan, et al., 2015). Karyawan perempuan menghadapi diskriminasi gender pada latar belakang tersebut. Perempuan tidak mendapatkan potensi gaji yang merupakan hak yang 
harus mereka dapatkan. Mereka mendapatkan gaji kurang dari karyawan laki-laki. Peluang Kerja Sama (Equal Employment Opportunity) disediakan oleh hukum untuk memastikan bahwa harus ada jaminan dari kesempatan kerja sama yang harus diberikan kepada tenaga kerja. Tenaga kerja adalah terdiri dari kedua jenis kelamin, yaitu laki-laki dan perempuan tetapi karyawan wanita menanggung diskriminasi gender dalam pekerjaan (Imam, et al., 2013).

Diskriminasi usia adalah perlakuan tidak adil dalam hal rekrutmen, promosi, atau pemberian hak istimewa di tempat kerja yang didasarkan atas usia dari seorang pekerja (Workplace Fairness, 2016). Diskriminasi merupakan faktor utama yang menghambat pekerjaan dari populasi yang menguntungkan dengan gender dan usia di tempat kerja. Diskriminasi dapat dikatakan sebagai perbedaan perlakuan kepada individu atau kelompok atas gender dan usia di tempat kerja.

\section{Stres Kerja}

Stres adalah ketegangan atau tekanan emosional yang dialami seseorang yang sedang menghadapi tuntutan yang sangat besar atau kesempatan melakukan sebuah kegiatan penting, yang dalam pemenuhannya terdapat hambatanhambatan dan ketidakpastian yang dapat mempengaruhi emosi, pikiran, dan kondisi fisik seseorang (Badeni, 2013).

Sehingga dapat disimpulkan bahwa stres kerja adalah respon dari seseorang terhadap lingkungan yang ada disekitarnya yang berpengaruh terhadap emosi, jalan pikiran, dan kondisi fisik seseorang.

Faktor yang mempengaruhi tingkat stres, yaitu pekerjaan dan lingkungan kerja (organisasi), lingkungan, dan faktor individu. Sumber stres dapat dikatakan sebagai stressor. Stressor yang dialami seseorang dapat berbeda antara satu orang dengan yang lain, walaupun mereka menghadapi stressor yang sama (Badeni, 2013). Faktor-faktor stres menurut Badeni
(2013) dibawah ini dapat digunakan sebagai alat untuk mengukur stres kerja yang mempengaruhi karyawan, yaitu:
a. Beban kerja,
b. Konflik peran,
c. Wewenang yang tidak seimbang,
d. Ketidakjelasan tugas,
e. Lingkungan kerja yang buruk,
f. Atasan yang tidak menyenangkan,
g. Rekan kerja yang tidak menyenangkan
h. Pengalaman.

\section{Komitmen Organisasi}

Komitmen organisasi adalah sejauh mana seorang karyawan mengidentifikasi dirinya dengan organisasi tertentu dan tujuan dan keinginan untuk mempertahankan keanggotaan dalam organisasi (Robbins \& Judge, 2011). Menurut Meyer karyawan memiliki tiga pola pikir yaitu komitmen afektif, normatif, dan berkelanjutan yang merupakan alat untuk mengukur komitmen organisasi (Robbins \& Judge, 2011). Hal tersebut untuk mengetahui bagaimana kelanjutan hubungan karyawan dengan organisasi.

Sehingga dapat disimpulkan bahwa komitmen organisasi adalah kondisi seseorang yang memihak organisasi tertentu sesuai dengan tujuan dan keinginannya untuk berada dalam organisasi tersebut.

\section{Penelitian sebelumnya}

Terdapat sebuah hubungan positif antara diskriminasi gender dan tingkat stres, yang berarti bahwa semakin tinggi diskriminasi gender maka semakin tinggi tingkat stress (Channar, et al., 2011). Ada hubungan positif antara stres kerja dan komitmen organisasi (Ziauddin, et al., 2010). Terdapat hubungan positif antara diskriminasi interpersonal dengan stres (O'Brien, et al., 2016). Komitmen organisasi dan kepuasan kerja secara 
negatif dipengaruhi oleh stres kerja (Masihabadi, et al., 2015). Stres memiliki pengaruh negatif terhadap komitmen organisasional, artinya semakin tinggi stres kerja yang dialami karyawan maka semakin rendah komitmen organisasional (Wibowo, et al., 2015). Dalam penelitian, terdapat hubungan antara diskriminasi kerja, stres kerja, dengan komitmen organisasi maka dapat disimpulkan bahwa kerangka pemikiran dari penelitian ini yaitu:

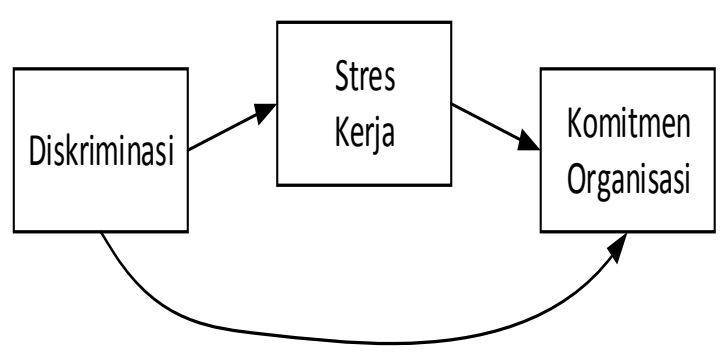

Gambar 1. Kerangka pemikiran.

\section{Hipotesis penelitian}

Hipotesis disusun berdasarkan kerangka pemikiran di atas, sehingga dapat dirumuskan sebagai berikut:

$\mathbf{H}_{\mathbf{1}}$ : Diskriminasi mempunyai pengaruh terhadap komitmen organisasi.

$\mathbf{H}_{\mathbf{2}}$ : Diskriminasi mempunyai pengaruh terhadap komitmen organisasi melalui stres kerja.

\section{METODE PENELITIAN}

Penelitian ini menggunakan tipe penelitian verifikatif. Dalam penelitian ini peneliti ingin mengetahui gambaran mengenai hubungan antara diskriminasi kerja, stres kerja, dengan komitmen organisasi.

Objek penelitian ini dilakukan di restoran Soerabi Bandung $\mathrm{HNH}$. Responden dari objek objek penelitiannya yaitu sebanyak 30 karyawan. Karyawan tersebut minimal sudah 6 bulan bekerja di Soerabi Bandung HNH. Teknik pengumpulan data penelitian ini menggunakan data primer atau sumber primer. Sumber primer adalah sumber data yang langsung memberikan data kepada pengumpul data (Sugiyono, 2013). Data primer dalam penelitian ini berupa kuesioner.

Teknik analisis data penelitian ini menggunakan analisa jalur (path analysis). Dengan metode tersebut maka dapat diketahui bagaimana pengaruh langsung dan tidak langsung. Hipotesis diuji menggunakan uji simultan (uji F) dan uji parsial (uji t atau $t$-test).

Operasionalisasi variabel yang digunakan dan sebagai acuan dalam penyusunan kuesioner ditampilkan dalam Tabel 1.

\section{PEMBAHASAN}

Hasil dari pengolahan data kuesioner yang diperoleh ditampilkan dalam Tabel 2.

\section{Analisis Hipotesis}

Pengujian ini dilakukan untuk mengetahui apakah variabel bebas yang digunakan dalam model secara parsial mempengaruhi variabel tidak bebasnya. Uji-t dilakukan dengan cara mengukur besarnya probabilitas t-statistik. Hipotesis yang digunakan adalah sebagai berikut:

Hipotesis yang diajukan untuk menguji signifikansi model fungsi biaya translog adalah sebagai berikut:

$$
\begin{gathered}
\mathrm{H}_{0} \quad: \beta=0, \\
\text { Variabel bebas tidak mempengaruhi } \\
\text { variabel tidak bebas secara signifikan. } \\
\mathrm{H}_{1} \quad: \beta \neq 0, \\
\text { Variabel bebas mempengaruhi } \\
\text { variabel tidak bebas secara signifikan. }
\end{gathered}
$$

Pengujian dilakukan dengan uji dua arah pada tingkat signifikansi $\alpha=0,05$. Kriteria yang berlaku: bila Prob t-statistik (p) $\leq$ 0.05, maka pengaruh variabel bebas tersebut terhadap variabel tidak bebas adalah signifikan. Sebaliknya bila Prob tstatistik $(p)>0.05$, maka pengaruh dari variabel bebas ini terhadap tidak bebas adalah tidak signifikan. 
Tabel 1. Operasionalisasi Variabel Dalam Penyusunan Kuesioner

\begin{tabular}{|c|c|c|}
\hline Variabel & Dimensi & Indikator \\
\hline Diskriminasi kerja & $\begin{array}{l}\text { Diskriminasi bervariasi pada faktor- } \\
\text { faktor sebagai berikut: } \\
\text { a. Gaji } \\
\text { b. Promosi } \\
\text { c. Perekrutan } \\
\text { d. Biologi }\end{array}$ & $\begin{array}{l}\text { Gaji : gaji sesuai dengan kesepakatan, lamanya } \\
\text { bekerja, dan kinerja. } \\
\text { Promosi : tersedia kesempatan promosi bagi } \\
\text { semua karyawan, promosi diketahui oleh } \\
\text { semua karyawan } \\
\text { Perekrutan : perekrutan sesuai dengan } \\
\text { persyaratan yang sudah ditetapkan, tidak ada } \\
\text { orang tertentu yang di prioritaskan } \\
\text { Biologi : perlakuan perbedaan berdasarkan } \\
\text { jenis kelamin dan umur }\end{array}$ \\
\hline Stres Kerja & $\begin{array}{l}\text { Faktor stres dari pekerjaan dan } \\
\text { lingkungan kerja dapat berupa: } \\
\text { a. Beban kerja, } \\
\text { b. Konflik peran, } \\
\text { c. Wewenang yang tidak seimbang, } \\
\text { d. Ketidakjelasan tugas, } \\
\text { e. Lingkungan kerja yang buruk, } \\
\text { f. Atasan yang tidak menyenangkan, } \\
\text { g. Rekan kerja yang tidak } \\
\text { menyenangkan. } \\
\text { h. Pengalaman }\end{array}$ & $\begin{array}{l}\text { Beban kerja : kesesuaian beban kerja dengan } \\
\text { kemampuan karyawan } \\
\text { Konflik peran : kesulitan menentukan prioritas } \\
\text { dalam menjalankan peran tertentu, kesulitan } \\
\text { pengambilan keputusan dalam menjalankan } \\
\text { pekerjaan } \\
\text { Wewenang yang tidak seimbang : kesesuaian } \\
\text { pekerjaan dengan job description dengan } \\
\text { tugas yang dikerjakannya } \\
\text { Ketidakjelasan tugas : Tidak adanya arahan } \\
\text { pengerjaan tugas, tidak adanya SOP, tugas } \\
\text { tersebut tidak ada penjelasan dari tujuan } \\
\text { pekerjaan } \\
\text { Lingkungan kerja yang buruk : kondisi tempat } \\
\text { bekerja yang kotor } \\
\text { Atasan yang tidak menyenangkan : } \\
\text { memperoleh kepercayaan dari atasan, } \\
\text { memperoleh penghargaan dari atasan atas } \\
\text { pekerjaan yang dilakukan } \\
\text { Rekan kerja yang tidak menyenangkan : } \\
\text { memperoleh kepercayaan dari rekan kerja, } \\
\text { dapat berinteraksi dengan rekan kerja } \\
\text { Pengalaman : diberikan kesempatan untuk } \\
\text { melaksanakan pekerjaan besar/penting }\end{array}$ \\
\hline Komitmen Organisasi & $\begin{array}{l}\text { Karyawan memiliki tiga pola pikir } \\
\text { yaitu komitmen afektif, normatif, } \\
\text { dan berkelanjutan. }\end{array}$ & $\begin{array}{l}\text { Komitmen afektif : memiliki kepercayaan } \\
\text { terhadap organisasi, memiliki ikatan emosional } \\
\text { dengan organisasi } \\
\text { Komitmen normatif : berkeinginan untuk } \\
\text { terus menjadi karyawan di perusahaan } \\
\text { Komitmen berkelanjutan : merasa rugi jika } \\
\text { meninggalkan perusahaan }\end{array}$ \\
\hline
\end{tabular}


Tabel 2. Hasil Estimasi

\begin{tabular}{|c|c|c|c|c|}
\hline & & & Estimate & $\mathbf{P}$ \\
\hline Stres Kerja & $<---$ & $\begin{array}{l}\text { Diskriminasi } \\
\text { Kerja }\end{array}$ & 1,152 & 0,011 \\
\hline $\begin{array}{l}\text { Komitmen } \\
\text { Organisasi }\end{array}$ & $<---$ & Stres Kerja & 0,821 & 000 \\
\hline $\begin{array}{l}\text { Komitmen } \\
\text { Organisasi }\end{array}$ & $<--$ & $\begin{array}{l}\text { Diskriminasi } \\
\text { Kerja }\end{array}$ & $-0,012$ & 0,098 \\
\hline
\end{tabular}

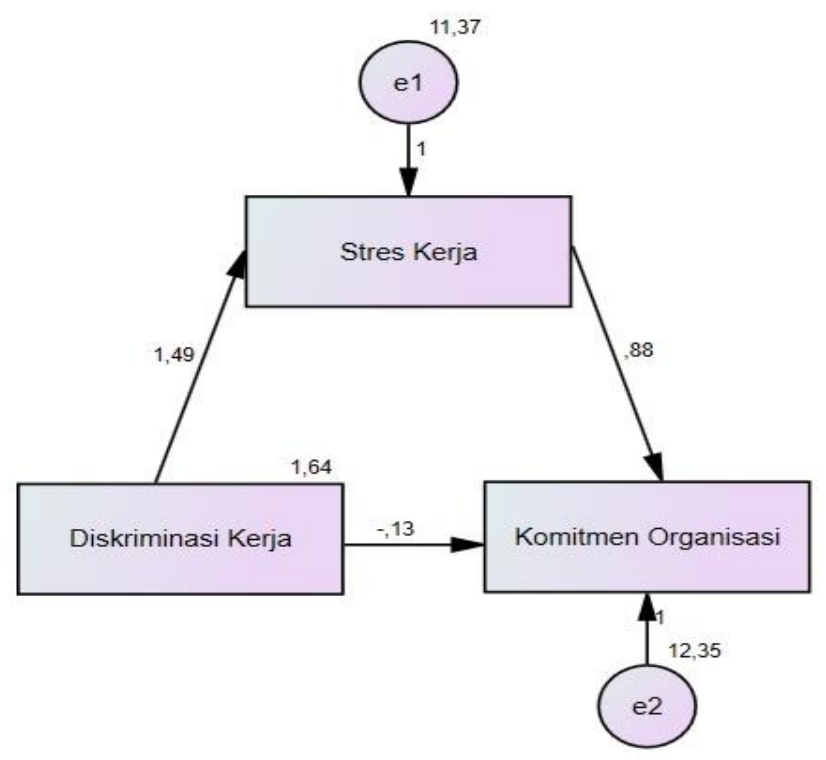

Gambar 2. Hasil AMOS

Pengaruh Diskriminasi Terhadap Komitmen Organisasi

Hasil penelitian menunjukkan bahwa diskriminasi tidak berpengaruh terhadap komitmen organisasi. Nilai $\mathrm{P}$ untuk Diskriminasi Kerja terhadap Stres Kerja sebesar 0.09 dan menunjukkan bahwa nilai tersebut lebih besar dari nilai $\alpha$ $=0.05$ maka dapat disimpulkan bahwa Diskriminasi Kerja tidak berpengaruh terhadap Komitmen Organisasi pada $\alpha=$ $5 \%$.

Berdasarkan analisa deskriptif (lampiran) pada variabel diskriminasi kerja dapat disimpulkan bahwa faktor gaji, jenis kelamin dan umur memiliki nilai rata-rata dibawah 3 artinya terjadi diskriminasi pada faktor gaji dan perekrutan. Sedangkan untuk indikator lainnya yaitu promosi dan perekrutan memiliki nilai rata-rata dibawah 4 . Hal ini dapat menjelaskan bahwa semakin tinggi perlakuan diskriminasi maka semakin rendah komitmen organisasi.

Pengaruh Diskriminasi Terhadap Komitmen Organisasi Melalui Stres Kerja

Hasil penelitian menunjukkan bahwa nilai $\mathrm{p}$ untuk pengaruh diskriminasi kerja terhadap stress kerja sebesar 0,01. Nilai tersebut lebih kecil dari nilai $\alpha=$ 
0,05. Hal tersebut menunukan bahwa Variabel Diskriminasi Kerja berpengaruh secara signifikan terhadap variabel Stres Kerja pada $\alpha=5 \%$. Nilai koefisien variabel Diskriminasi Kerja terhadap Stres Kerja sebesar 1,152. Artinya setiap kenaikan variabel Diskriminasi Kerja sebesar 1 poin dengan asumsi variabel lain tetap maka akan meningkatkan Stres Kerja sebesar 1,152 poin. Hal ini menunjukkan bahwa diskriminasi yang terjadi di restoran berpengaruh terhadap stres kerja karyawan. Beberapa faktor yang menyebabkan stres kerja yaitu beban kerja, konflik peran, wewenang yang tidak seimbang, ketidakjelasan tugas, lingkungan kerja yang buruk, atasan yang tidak menyenangkan, rekan kerja yang tidak menyenangkan, dan pengalaman yang diberikan kepada karyawan. Karyawan yang mengalami diskriminasi akan merasakan stres kerja yang dapat mempengaruhi emosi, pikiran, dan kondisi fisiknya. Ketika karyawan terganggu emosi, pikiran, dan kondisi fisiknya maka dapat mempengaruhi kinerja ketika memberikan pelayanan kepada pelanggan, sehingga dapat memungkinkan memberikan kesan yang buruk bagi restoran.

Hasil penelitian menunjukkan bahwa nilai $\mathrm{p}$ untuk pengaruh diskriminasi kerja terhadap komitmen organisasi sebesar 0,00. Nilai tersebut lebih kecil dari nilai $\alpha=0,05$. Artinya, Variabel Stres Kerja berpengaruh secara signifikan terhadap variabel Komitmen Organisasi pada $\alpha=5 \%$. Nilai koefisien variabel Stres Kerja terhadap Komitmen Organisasi sebesar 0,821. Artinya setiap kenaikan variabel Stres Kerja sebesar 1 poin dengan asumsi variabel lain tetap maka akan meningkatkan Komitmen Organisasi sebesar 0,821 poin. Hal ini menunjukkan bahwa stres kerja yang dialami oleh karyawan restoran dapat mempengaruhi keinginan dan tujuan individu terhadap organisasi. Seperti karyawan menjadi tidak ingin bekerja untuk restoran dalam jangka waktu yang panjang.
Diskriminasi Kerja memiliki pengaruh terhadap Komitmen Organisasi melalui Stres Kerja. Di restoran ditemukan beberapa praktek diskriminasi ringan seperti dalam faktor gaji, promosi, perekrutan, gender dan usia. Sesuai dengan fenomena yang ada ditempat penelitian, hal ini menyebabkan stres kerja yang ditunjukkan melalui beban kerja, konflik peran, lingkungan kerja yang buruk, atasan yang tidak menyenangkan, rekan kerja yang tidak menyenangkan, dan pengalaman. Hal tersebut pada akhirnya mempengaruhi komitmen organisasi karena karyawan yang mengalami stres dalam bekerja akan mempengaruhi keinginan mereka untuk tetap berada di restoran maupun kepercayaan terhadap restoran yang mereka yakini akan memberikan yang terbaik untuk mereka.

Dalam penelitian ini ditemukan hal yang berbeda terhadap komitmen, dampak stress kerja ternyata memiliki dampak positif senilai 0,821. Dari hasil observasi dan wawancara dan analisa statistik deskriptif hasil kuesioner (lampiran), dapat disimpulkan bahwa walaupun mereka mengalami stress kerja, namun hal tersebut telah mereka sadari dan menjadi konsekuensi umum ketika bekerja menjadi karyawan. Sehingga kondisi tersebut tidak berdampak negatif terhadap komitmen organisasi.

\section{KESIMPULAN}

Pada restoran Soerabi Bandung $\mathrm{HNH}$, Diskriminasi kerja tidak berpengaruh secara langsung terhadap komitmen organisasi, yang ditunjukan dengan nilai $\mathrm{p}=0,098$. Namun Diskriminasi Kerja berpengaruh terhadap Komitmen Organisasi melalui Stres Kerja. Hal in ditunjukan dengan nilai $\mathrm{p}$ dari estimasi pengaruh diskriminasi kerja terhadap stress kerja sebesar 0,01 dan nilai $\mathrm{p}$ dari estimasi pengaruh stres kerja terhadap komitmen organisasi sebesar 0,00 .

Hasil analisa data menunjukan memang terjadi diskriminasi kerja seperti 
pengaturan jam kerja, peluang promosi, ketidak jelasan tugas dan pembagian beban kerja sehingga menyebabkan karyawan merasa diperlakukan tidak adil dan mengalami stres kerja. Restoran Soerabi Bandung $\mathrm{HNH}$ perlu memastikan tidak terjadi diskriminasi kerja sehingga dapat mengurangi stress kerja dan meningkatkan komitmen karyawan pada organisasinya. Pada kahirnya hal tersebut akan berdampak positif terhadap perusahaan. tanpa diskriminasi kerja dan stres kerja, karyawan menjadi percaya dengan perusahaananya, memiliki ikatan dan berkeinginan untuk menjadi bagian dari perusahaan tersebut dengan memberikan kontribusi kerja terbaik.

\section{DAFTAR PUSTAKA}

1. Arifin, J., \& Fauzi, A. (2007). Aplikasi Excel dalam Aspek Kuantitatif Manajemen Sumber Daya Manusia. Jakarta: PT Elex Media Komputindo.

2. Badeni. (2013). Kepemimpinan \& Perilaku Organisasi. Bandung: ALFABETA, cv.

3. Channar, Z. A., Abbassi, Z., \& Ujan, I. A. (2011). Gender Discrimination in Workforce and its Impact on the Employees. 190.

4. Eurofound. (2012). Diambil kembali dari http://www.eurofound.europa.eu/

5. Imam, A., \& Shah, F. T. (2013). Impact of gender bias on organizational commitment: an empirical study of glass ceiling practices in corporate sector of Pakistan. Elixir International Journal, 14111. Dipetik October 9, 2016, dari http://www.elixirpublishers.com/articl es/1365138015_57\%20(2013)\%20141 11-14115.pdf

6. Kadiresan, V., \& Javed, N. K. (2015). Discrimination in Employment and Task Delegation at Workplace in the Malaysian Context. International Journal of Academic Research in Business and Social Sciences, 29-41.
7. Masihabadi, A., Rajaei, A., Koloukhi, A. S., \& Parsian, H. (2015). Effects of stress on auditors' organizational commitment, job satisfaction, and job performance. International Journal of Organizational Leadership, 312. Dipetik October 9, 2016, dari http://papers.ssrn.com/sol3/papers.cfm ?abstract_id=2641246

8. O'Brien, K. R., McAbee, S. T., Hebl, M. R., \& Rodgers, J. R. (2016). The Impact of Interpersonal Discrimination and Stress on Health and Performance for Early Career STEM Academicians. Frontiers in Psychology. Dipetik October 9, 2016, dari

https://www.ncbi.nlm.nih.gov/pmc/art icles/PMC4849428/

9. Robbins, S. P., \& Judge, T. A. (2011). Organizational Behavior (14th edition ed.). New Jersey: Prentice Hall

10. Suardi, S. (2016). Implikasi Sosial Diskriminasi Gender (Studi Tentang Gender Di Kampung Bungung Katammung Kabupaten Bantaeng). Jurnal Sosiologi Pendidikan Humanis, 41-45.

11. Sugiyono, P. D. (2013). Metode Penelitian Manajemen. Bandung, Jawa Barat: CV Alfabeta.

12. Wibowo, G. P., Riana, G., \& Putra, M. S. (2015). Pengaruh Stres Kerja Terhadap Kepuasan Kerja Dan Komitmen Organisasional Karyawan. E-Jurnal Ekonomi dan Bisnis Universitas Udayana, 137. Dipetik Oktober 9, 2016

13. Workplace Fairness. (2016). Age Discrimination. Diambil kembali dari Workplace Fairness: http://www.workplacefairness.org/age -discrimination\#maincontent

14. Yani, M. (2012). Manajemen Sumber Daya Manusia. Jakarta: Mitra Wacana Media. Dipetik Oktober 11, 2016

15. Ziauddin, Khan, M. R., Jam, F. A., \& Hijazi, S. T. (2010). The Impacts of Employees Job Stress on Organizational Commitment. 
European Journal of Social Sciences, 13, 619. Dipetik October 9, 2016, dari http://ejournal.narotama.ac.id/files/ejs s_13_4_12.pdf 


\section{Lampiran}

Tabel statistik deskriptif

\begin{tabular}{|c|c|c|c|c|c|c|}
\hline & & $\mathrm{N}$ & Minimum & Maximum & Mean & Std. Deviation \\
\hline \multirow[t]{2}{*}{ Gaji } & DK1 & 30 & 3,00 & 5,00 & 4,1333 & ,62881 \\
\hline & DK2 & 30 & 2,00 & 5,00 & 3,7333 & ,82768 \\
\hline \multirow[t]{2}{*}{ Promosi } & DK3 & 30 & 2,00 & 5,00 & 3,6333 & 85029 \\
\hline & DK4 & 30 & 2,00 & 5,00 & 4,0667 & ,69149 \\
\hline \multirow[t]{2}{*}{ Perekrutan } & DK5 & 30 & 2,00 & 5,00 & 3,9333 & ,73968 \\
\hline & DK6 & 30 & 1,00 & 5,00 & 3,9333 & ,86834 \\
\hline \multirow[t]{3}{*}{ Boilogi (gender dan usia) } & DK7 & 30 & 1,00 & 5,00 & 3,6333 & 1,15917 \\
\hline & DK8 & 30 & 1,00 & 5,00 & 2,3000 & 1,17884 \\
\hline & DK9 & 30 & 1,00 & 5,00 & 2,6667 & 1,24106 \\
\hline \multirow[t]{2}{*}{ Beban kerja } & SK10 & 30 & 2,00 & 5,00 & 4,0000 & ,64327 \\
\hline & SK11 & 30 & 1,00 & 5,00 & 3,2000 & 1,09545 \\
\hline \multirow[t]{2}{*}{ Konflik kerja } & SK12 & 30 & 2,00 & 5,00 & 3,9333 & ,78492 \\
\hline & SK13 & 30 & 1,00 & 5,00 & 2,9000 & ,95953 \\
\hline \multirow[t]{2}{*}{ Wewenang kerja } & SK14 & 30 & 1,00 & 5,00 & 2,6333 & 1,03335 \\
\hline & SK15 & 30 & 2,00 & 5,00 & 3,9333 & ,63968 \\
\hline \multirow[t]{2}{*}{ Kejelasan tugas } & SK16 & 30 & 2,00 & 5,00 & 4,0667 & ,78492 \\
\hline & SK17 & 30 & 3,00 & 5,00 & 4,0667 &, 52083 \\
\hline Lingkungan kerja & SK18 & 30 & 1,00 & 5,00 & 3,6667 & ,99424 \\
\hline Hubungan dg atasan & SK19 & 30 & 3,00 & 5,00 & 4,1000 & ,40258 \\
\hline Hubungan dg rekan & SK20 & 30 & 3,00 & 5,00 & 4,1667 & ,59209 \\
\hline Pengalaman & SK21 & 30 & 2,00 & 5,00 & 3,8333 & ,79148 \\
\hline \multirow[t]{2}{*}{ Komitmen afektif } & KO22 & 30 & 1,00 & 5,00 & 3,5000 & 86103 \\
\hline & $\mathrm{KO} 23$ & 30 & 2,00 & 5,00 & 3,7000 & ,65126 \\
\hline \multirow[t]{2}{*}{ Komitmen normatif } & KO24 & 30 & 1,00 & 5,00 & 3,4000 & 1,00344 \\
\hline & $\mathrm{KO} 25$ & 30 & 1,00 & 5,00 & 3,6667 & 84418 \\
\hline \multirow[t]{4}{*}{ Komitmen berkelanjutan } & KO26 & 30 & 1,00 & 5,00 & 3,2000 & 84690 \\
\hline & KO27 & 30 & 2,00 & 5,00 & 3,2667 & ,73968 \\
\hline & $\mathrm{KO} 28$ & 30 & 1,00 & 5,00 & 3,3667 & ,85029 \\
\hline & $\begin{array}{l}\text { Valid N } \\
\text { (listwise) }\end{array}$ & 30 & & & & \\
\hline
\end{tabular}

